\title{
Monitoring Carbon Dioxide in the Atmosphere and Heavy Metals in Runoff Water at Active Landfill, Retired Landfill, and Forest Control Sites to Determine Remediation Effectiveness
}

\author{
Jesse Banick, Kathryn Lenz, Jonathan Sanders, \\ Jeshanah Zolkowski ${ }^{1}$ \\ University of Wisconsin - Fox Valley, Menasha
}

\begin{abstract}
With the exponential growth of the human population and the focus on "Westernizing" the globe, waste and landfill use has spread. This makes the search for better remediation methods imperative. This paper describes the environmental impact of an active and a retired landfill. Carbon dioxide levels in ambient air and heavy metal concentrations in runoff water were monitored at both landfills and a control site. Data showed a significant difference in carbon dioxide levels among the sites, with the active landfill having the highest concentration and the control site having the lowest. Heavy metal tests revealed higher concentrations of lead and copper at the retired landfill compared to the active landfill and control site. The collected data is not sufficient to make a broad conclusion about remediation effectiveness; therefore, the researchers encourage continued investigation of this topic.
\end{abstract}

\section{Introduction and Literature Review}

Landfills and carbon dioxide. Active and retired landfills release carbon dioxide and other gases as microorganisms degrade the waste inside. In order to contain and reduce these emissions, researchers have investigated how different capping and seeding techniques affect the environment around retired landfills. The resulting vegetation that grows helps to control carbon dioxide emissions through photosynthesis. The vegetation selected for seeding is important, as different species will thrive better in certain climates, soil compositions, and ecological systems (Banick, Lenz, Sanders, \& Zolkowski, 2015). For this experiment, three sites were tested: Outagamie County Landfill (active landfill), Lehrer Landfill (retired landfill), and High Cliff State Park (control site). High Cliff State Park was chosen as the control site due to its close proximity to the landfills being examined and because it was far from potential contamination.

History of carbon dioxide monitoring. Research on greenhouse gas levels in the atmosphere has been a point of interest for more than five decades, with scientist Charles David Keeling spearheading continual measurement efforts in the mid-1900s. At the Mauna Loa Observatory in Hawaii, Keeling implemented infrared sensors to measure the levels of carbon dioxide and analyze patterns in the data. He discovered that carbon dioxide levels are increasing globally (Roston, 2008).

1This research was made possible by Wisconsin Space Grant Consortium, NASA, Dan Hawk, Dave's Sport and Marine, Outagamie County Landfill, City of Kaukauna, High Cliff State Park, Weld Specialty in Kaukauna, WEAL at UW Steven's Point, Beth A. Johnson, Joy Perry, Brian Rukamp, Martin Rudd, other UW Fox Valley Faculty, Van Groll Trucking, and our Affiliate Student Interns (Skander Desrosiers, Zach Dorn, John Gara, Leigh Hayes, Cassondra Parsons, Erika Petersen, Katie Stadler, William Talbot, Tristan Tully, and Logan Vandecorput). 
Greenhouse gases and climate change. The greenhouse effect, a cause of global climate change, is the most concerning consequence of rising carbon dioxide concentrations.

Carbon dioxide traps some of the sun's radiation within the Earth's atmosphere, which in turn produces warming of the global temperature (Climate Central, 2012). Given enough carbon dioxide, a runaway greenhouse gas effect could occur. For example, global warming could initiate forest fires, which in turn would leave less vegetation. Losing vegetation would hinder carbon capture, again contributing to higher greenhouse gas concentrations (Feldscher, 2011). Another theory describes more localized abnormalities, which could possibly change weather patterns and gravely affect local ecological systems ("Climate Change Causes," n.d.). Since climate change could lead to so many far-reaching problems, ways to prevent or reduce it must be examined. The Environmental Protection Agency (EPA) reported around 3,500 landfills in the United States as of 2012, so mitigating carbon dioxide emissions at all these sites is of great importance (U.S. Environmental Protection Agency, 2012). Better remediation processes could help slow the trend on increasing carbon dioxide levels.

\section{Methods}

Location of active landfill, retired landfill, and control site. The active, retired, and control sites are all located in relatively close proximity to one another (Fig. 1) in Northeast Wisconsin, near Lake Winnebago (Banick et al., 2015).

Tethered Aerostat. The field area was studied using data collected from a payload that hung beneath a Lighter Than Air

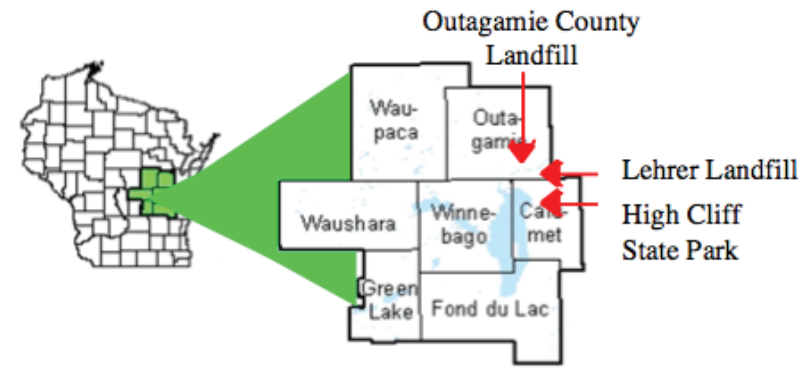

Fig. 1: Map of field sites. Source: Fox Valley Technical Colege Systems (LTAS) Kingfisher Aerostat K7.5U filled with approximately 230 cf of helium. The aerostat collected data for about 30 minutes at the three sites from about $150 \mathrm{~m}$ above ground level.

\section{Carbon dioxide concentration, GPS,} and altitude data. A K-30 carbon dioxide sensor, which used a nondispersive infrared waveguide system to measure the gas, was mounted to the payload. The sensor could detect carbon dioxide concentrations between $0 \mathrm{ppm}$ and 2,000 ppm with a sensitivity of $1 \%( \pm 20 \mathrm{ppm})$ and accuracy of $3 \%$

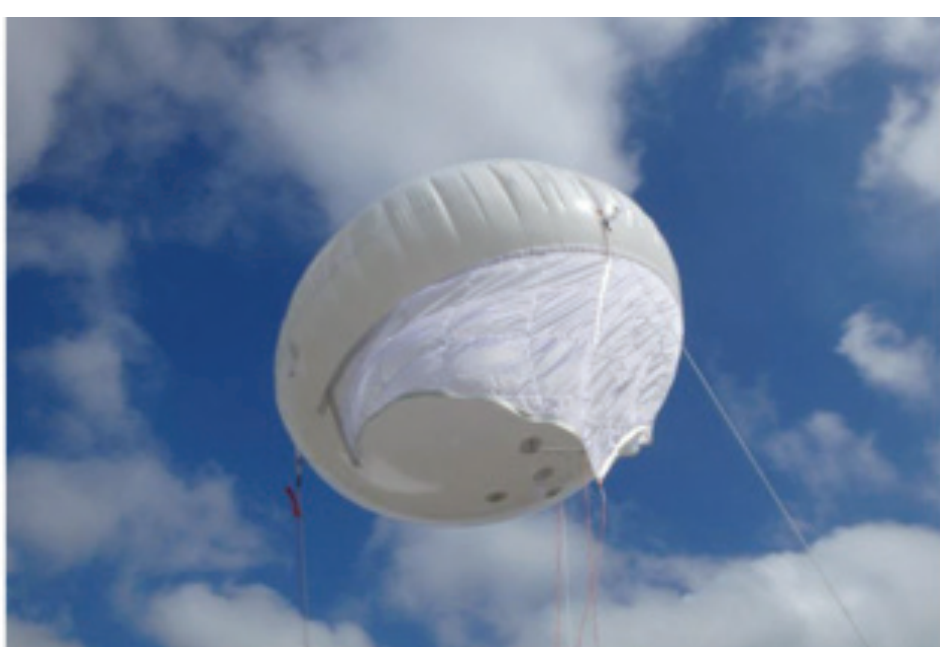

Fig. 2: The payload was suspended by ropes below the aerostat. Photo by Beth Johnson

( \pm 30ppm) ("Datasheet: K-30 Sensor," 2015). The relatively large uncertainty associated with 
individual values was decreased by comparing each location's mean carbon dioxide concentration. Data was sent to an Arduino Uno for information storage. Another payload component, the GPS Aim XTRA (GAX), recorded altitude and GPS coordinates. A ground computer retrieved the data with the Aim Base.

NDVI photography. The ADC Micro spectral imaging camera, manufactured by Tetracam, took .RAW images every 60 seconds during each launch. These images were saved to a MicroSD card. Images were imported into Pixelwrench 2, a software developed by Tetracam, and batch processed to give pictures that were color-coded based on the normalized difference vegetation index (NDVI) value of each pixel. The overall NDVI of each image was also calculated (Eq 1).

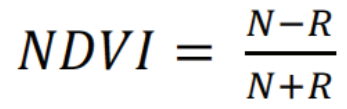

(Eq. 1)

NDVI is a mathematical tool for comparing the amount of near infrared $(\mathrm{N})$ and red (R) light reflected from a sample. When an image is taken with a spectral imaging camera and analyzed, each pixel has a certain amount of red and near infrared light associated with it. Photosynthesizing plants often reflect near infrared while absorbing red light. Other objects tend to absorb infrared. The NDVI value of a photosynthesizing plant would ideally result from a constant value of $\mathrm{N}$ and a minute value of $\mathrm{R}$. In the limit that the value of $\mathrm{R}$ is small, the NDVI value nears one. The NDVI value of an abiotic object can be generated by holding $R$ constant and taking the limit of the NDVI as N nears zero, leading to a negative one ("An Introduction...," n.d.). In practice, the values range between these extremes, rarely reaching one or negative one.

Heavy metal concentrations. Water samples were taken from bodies of water that were believed to be directly influenced by the launch sites as they were each in a position directly below those sites. These samples were taken from each location in November 2015 (fall), March 2016 (spring), and in July 2016 (summer) in order to achieve a comparison between the concentrations throughout seasonal variations. The collected samples were sent to the Water and Environmental Analysis Lab (WEAL) at UW- Steven's Point, which was able to analyze the samples with the Agilent Technologies 700 Series ICP-OES. With this spectrometer, the concentrations of 22 different metals were detected if they were in the sample. This data was used to compare the logistical and geographical aspects of each site to determine why the results may vary other than for the fact that two sites are landfills and one is a control. This information was intended to complement the atmospheric portion of the research by getting as much information as possible on each experimentation site in an attempt to understand them in their entirety.

Power supply and payload board. All of the equipment on the wooden payload board was arranged to keep the centroid in the middle of the board. Three ropes stretched from the board to a swivel that connected the payload to the balloon cords. The components on the board drew power from two 11.4mAh LiPo batteries. One battery fed the GAX and ADC Micro, while the other fed the Arduino and K-30 sensor.

\section{Data and Observations}

Carbon dioxide concentration. The carbon dioxide and altitude data collected is represented below. (Fig. 4) includes data taken from the control site, High Cliff State Park, and represents 
the concentration (ppm) of carbon dioxide over time. The sensor being used to monitor carbon dioxide levels gave very sporadic readings. It is believed this was due to the instability of the tethered aerostat and limitations of the sensor being used, thus it was deemed a simple average over time was best indicator of approximate carbon dioxide levels. (Fig. 5 and 6) are done in the same manner for the data taken at both landfills. It is worth noting here that the global average for carbon dioxide concentration in the atmosphere is approximately $400 \mathrm{ppm}$.

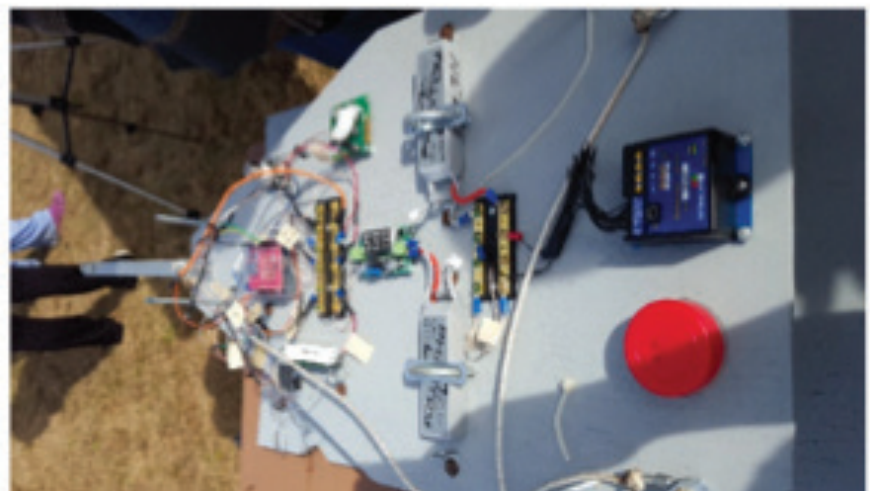

Fig. 3: Equipment was mounted on the payload board. Photo by Jonathan Sanders

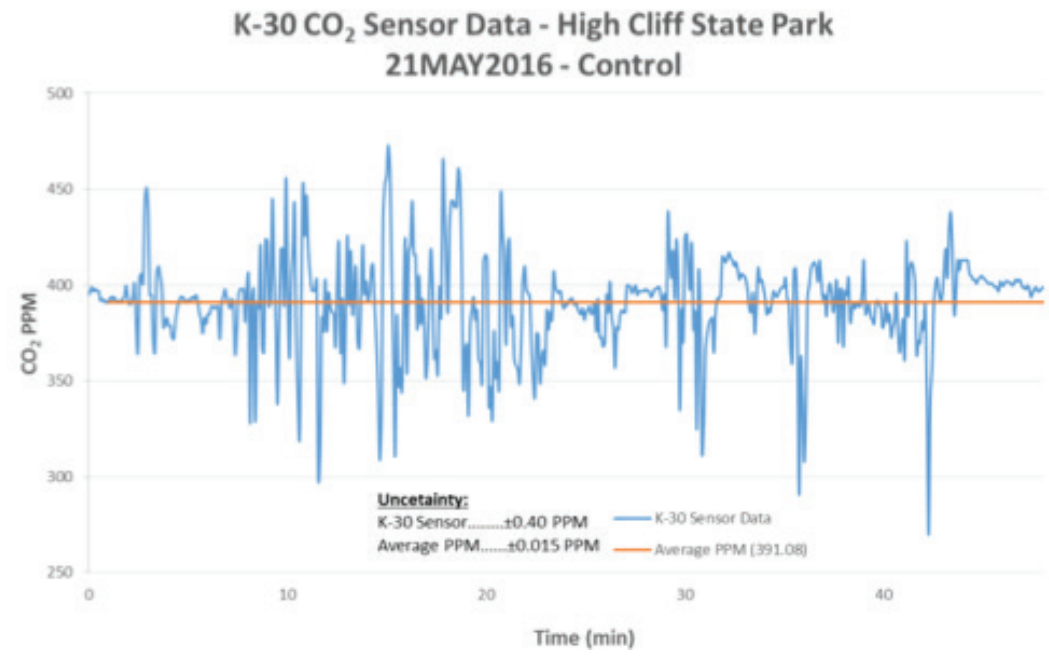

Fig. 4: $\mathrm{CO}_{2}$ concentrations measured in ppm, over time, at High Cliff State

Park (control site). The average ppm was approximately 391.08 ppm.

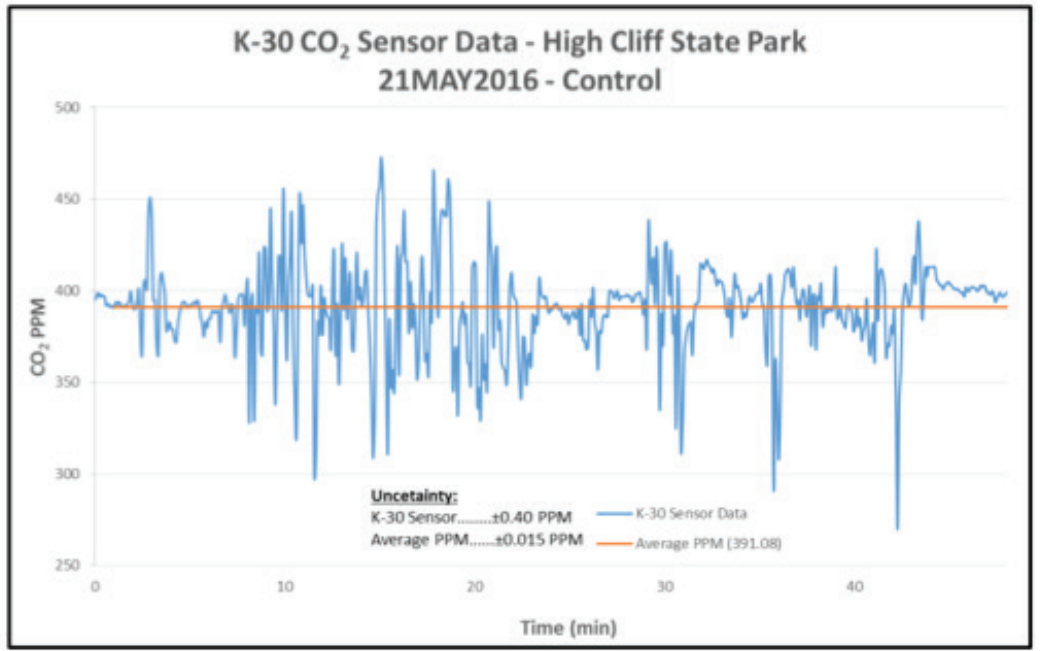

Fig. 5: $\mathrm{CO}_{2}$ concentrations measured in ppm, over time, at Lehrer Landfill (retired site). The average ppm was approximately $397.44 \mathrm{ppm}$ (an increase of $1.63 \%$ from the control). 


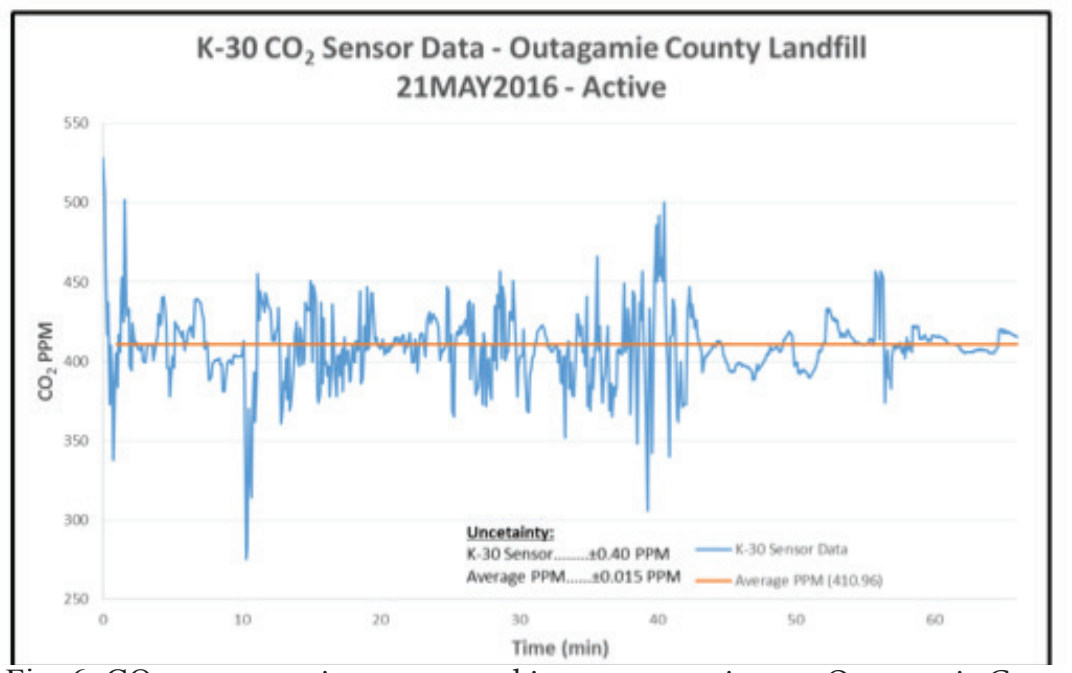

Fig. 6: $\mathrm{CO}_{2}$ concentrations measured in ppm, over time, at Outagamie County Landfill (active site). The average ppm was approximately 410.96 ppm (an increase of $1.63 \%$ from the control).

NDVI photography. The images obtained from Van Groll Trucking (northeast of Outagamie County Landfill) and Lehrer Landfill were processed using Pixelwrench 2. The NDVI value of each overall picture was obtained. A line graph of the NDVI of the images over time was created to analyze trends.

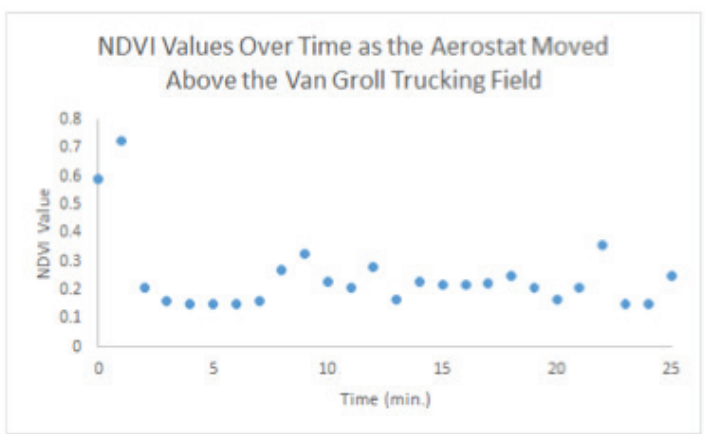

Fig. 7: NDVI values of the images taken above the Van Groll Trucking field.

a)
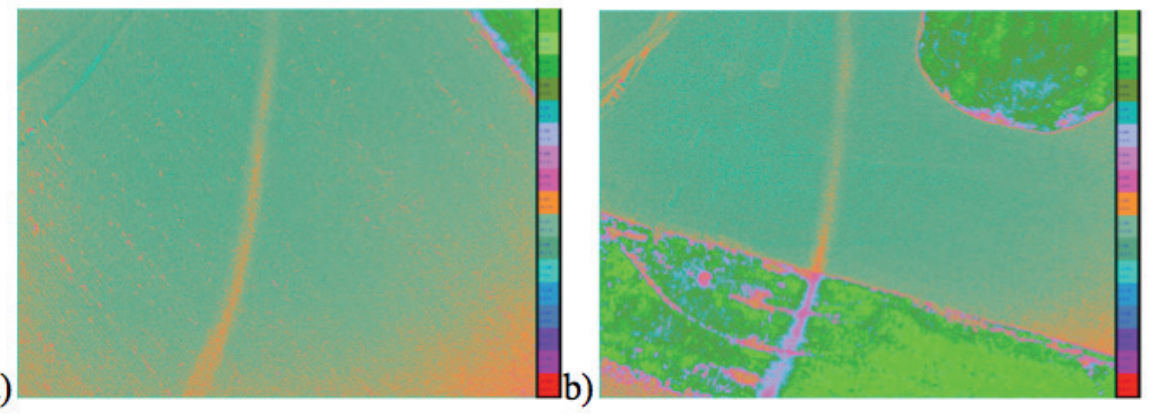

Fig. 8: NDVI images taken at 20 minutes (a) and 22 minutes (b). Each pixel has been assigned a color corresponding to its NDVI value. The color-NDVI correspondence is shown on the right of each image, with NDVI values close to 1 represented by a bright green and NDVI values close to -1 represented by a bright red. 
The time graph from Van Groll Trucking (Fig. 7) accurately predicts when the aerostat was above vegetation and dirt, but is misleading when the payload was on the payload stand. The pictures taken at 0,1 , and 2 minutes have the highest NDVI values in the graph. These were the pictures taken when the camera was above the wooden, silver- painted board and when it was above a person during the lift-off stage. These results do not match the predicted NDVI values, because a high NDVI is supposed to indicate healthy vegetation. In this case, a high NDVI was recorded even though no vegetation was present in the image. In spite of this discrepancy, the rest of the graph matches expectations. The pictures taken from 2 to 7 minutes had a large area of dirt, which agrees with the low NDVI values. At 8 minutes and 12 minutes, there was a slightly greater vegetative region captured by the camera. The picture taken at 20 minutes (Fig. 8a.) had very little vegetation in view, which is represented by a dip in the graph. The time when the most vegetation was captured occurred at 22 minutes (Fig. 8b.), which was seen both in the picture and is demonstrated by a high NDVI in the graph. This data seems to show that NDVI accurately reflects the amount of vegetation in images with dirt and vegetation but does not accurately predict vegetation cover when reflective objects are in view.

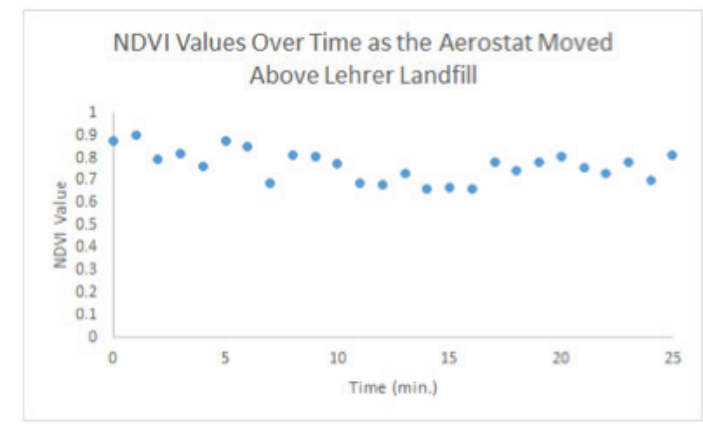

Fig. 9: NDVI values of the images taken above retired Lehrer Landfill

a)
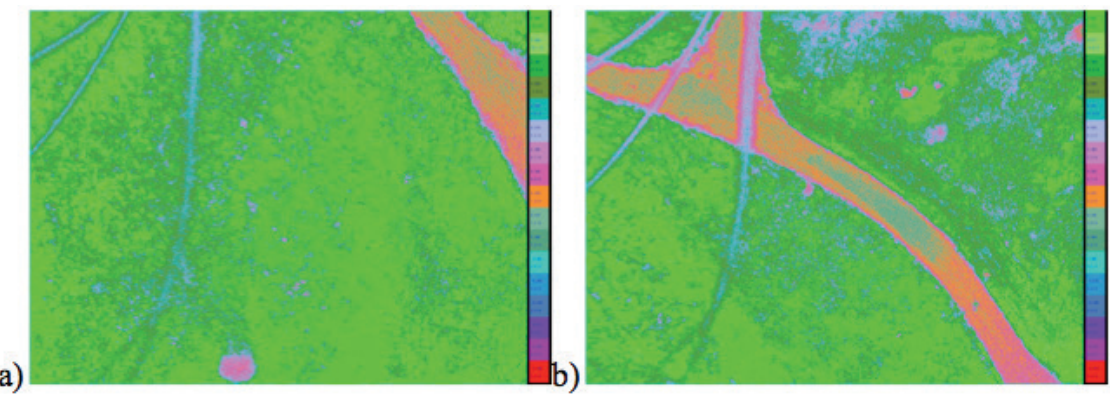

Fig. 10: NDVI images taken at 10 minutes (a) and 11 minutes (b). Each pixel has been assigned a color corresponding to its NDVI value. The color-NDVI correspondence is shown on the right of each image, with NDVI values close to 1 represented by a bright green and NDVI values close to -1 represented by a bright red.

The NDVI values above Lehrer Landfill were much more stable, since the aerostat was constantly above vegetation. There is one notable trend. Between 11 and 21 minutes, the picture taken by the camera had some of the gravel path in the field of view ( Fig. 10). This can be seen by the slightly lower NDVI values in the graph during this time interval. 
The NDVI values for this launch matched the expectations. In addition, the NDVI values stayed above .6, showing that the vegetation at Lehrer Landfill was fairly healthy.

Heavy metal concentrations. With the data that was received from the help at UW- Stevens Point, two comparisons were made. First, the concentrations at each launch site were compared in order to get an idea of their relative water quality (Fig. 11-13). Then for each launch site, a comparison was made between the three dates that samples were taken as a way to see how seasonal effects impacted the data (Fig. 14). All of the graphs in the same figure are from the same data set; however, they needed to be comprised into separate graphs due to the variance in the concentration values. A lack of permission to enter the Outagamie County Landfill during the last two launches resulted in the inability to make that seasonal change comparison.

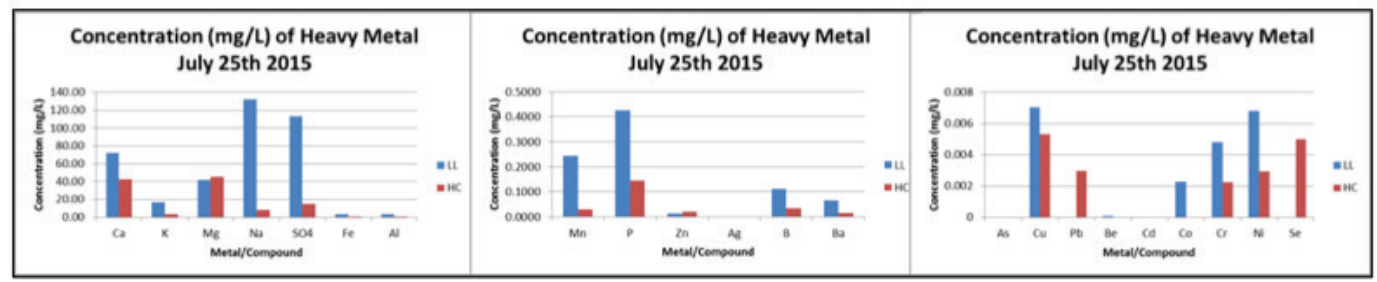

Fig. 11: The heavy metal ion concentration in the runoff water for each launch site on July 25th, 2015.

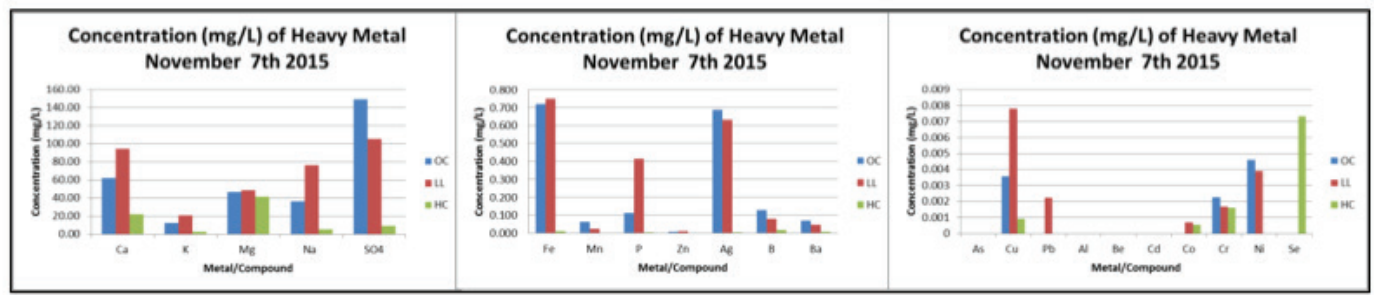

Fig. 12: The heavy metal concentration in the runoff water for each launch site on November 7th, 2015.

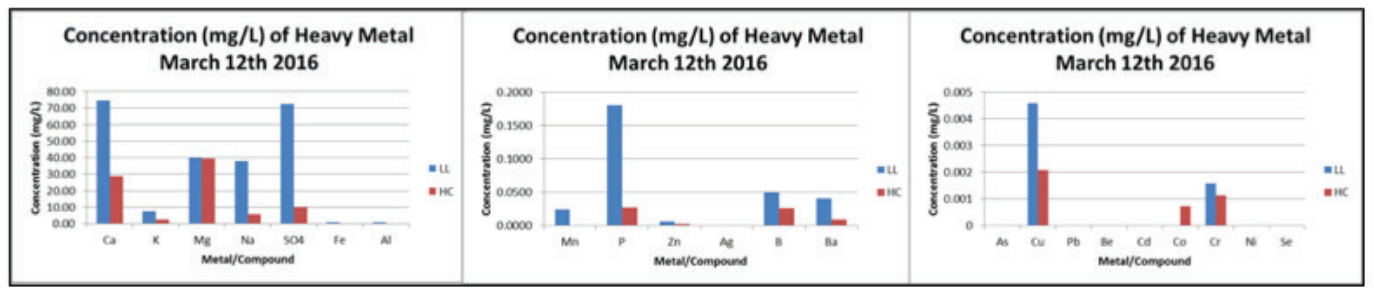

Fig. 13: The heavy metal ion concentration in the runoff water for each launch site on March 12th, 2016.

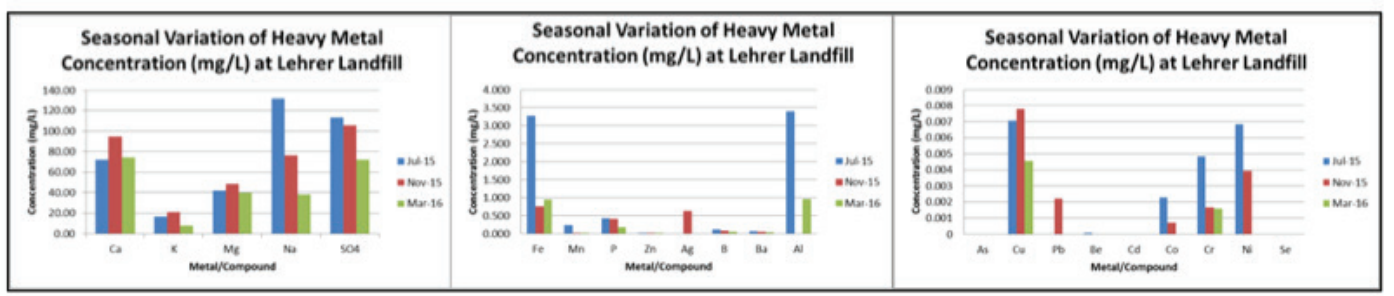

Fig. 14: The heavy metal ion concentration at Lehrer Landfill throughout seasonal variations. 


\section{Discussion}

Carbon dioxide concentration. The average carbon dioxide concentrations increased in order from the control site $(\sim 391 \mathrm{ppm})$, to the retired site $(\sim 397 \mathrm{ppm})$, and finally to the active site $(\sim 411$ ppm). This was expected as it was previously known that landfills are a source of carbon dioxide emissions. The spikes in concentration (Fig. 4-6) are likely due to the instability inherent in the aerostat. Though altitude data was gathered, there was not any drastic changes in the average carbon dioxide concentration between ground level and our maximum elevations; thus it is has not been represented in the data.

In this study, researchers measured gas concentrations in the ambient air. This measurement does not indicate the actual rate of gas emission, as carbon dioxide diffuses after being emitted. Measuring ground emissions accurately requires that a specific area of the landfill be enclosed to avoid wind and diffusion factors (Perera, Hettiaratchi, and Achari, 2002). This precaution was not taken in this study due to equipment restraints.

NDVI photography. The plant life at Lehrer Landfill seems fairly healthy, with whole- picture NDVI values ranging from .65 to .9 (the images on the low portion of this range included large sections of the gravel trail). Unfortunately, aerial pictures at Outagamie County Landfill and High Cliff State Park could not be obtained for NDVI comparison.

Heavy metal concentrations. The concentration of heavy metal ions was generally far lower at the control than the other two launch sites, as expected. As for the comparison between the retired and active landfill, the retired site exhibited slightly more frequent higher values than did the active. With that, when the retired site had the highest value, there was overall a greater difference between that value and the one that followed. Finally, for the seasonal comparison, the July launch seemed to have the greatest values of heavy metal ion concentration and the March launch had the lowest. The seasonal variation at the control site had a similar result and therefore was omitted. Note, if a metal/compound has no bar associated with it the value is not necessarily zero; however, it was below the detectable level.

\section{Conclusion}

Carbon dioxide concentration. The average carbon dioxide concentration at High Cliff State Park, the control site, was well below the approximate global average of $400 \mathrm{ppm}$. As a clean air environment, this was expected. At Lehrer Landfill, the retired site, the average carbon dioxide concentration was elevated from the control site; but it was still slightly below the approximate global average. It is believed that this is due to the capping and remediation efforts in place at the retired site. The highest average carbon dioxide concertation was found at Outagamie County Landfill, the active site. The active site was the only one with a concentration higher than that of the approximate global average. However, this site lies right next to a major highway (I-41), and the carbon dioxide emissions from this highway were not controlled or accounted for in this analysis. Overall, carbon dioxide emissions at both landfills seem to be under reasonable control, and remediation seems effective. Unfortunately only one qualitative set of data was collected from each site, so these results are preliminary. If a definitive conclusion is to be made, continued seasonal measurements must be taken; and other carbon dioxide sources (automotive traffic, industry emissions, etc.) must be controlled or accounted for. 
NDVI photography. The NDVI plant health assessment algorithm works well when used to compare different vegetation and some inanimate objects. At Van Groll Trucking and Lehrer Landfill, it accurately mimicked the vegetation cover in the images of soil and plant areas. On the other hand, it gave misleading values when above painted objects and human beings. These findings highlight the importance of ground tests and site familiarity when using NDVI.

Heavy metal concentrations. While it is intuitive that the control site generally experienced lower values of heavy metal ion concentrations in its runoff water, the reasoning for the retired landfill having the highest values is not as clear. One thought is that the retired landfill was in commission during a time that was less regulated compared to today's standards. Another thought is that the nature of these bodies of runoff water is different and therefore may have affected the outcome of these tests. Regardless of these possibilities, the actions taken at the active landfill seem to be doing a better job at remediating the effects of the landfill.

General Conclusion. Though the data gathered seems to show a correlation between landfills the concentrations of carbon dioxide in the air and heavy metals in the water, nothing definitive can be stated; the sample sizes were inadequate. It does appear that local vegetation and other remediation methods, such as capping, are effective in limiting potentially harmful emissions from landfills. To better understand the relationship between landfills and these emissions, and to perhaps develop new remediation methods, further research must be conducted.

References

An Introduction to Multispectral Imaging and How Growers and Other Users Benefit from this Technology. (n.d.). Retrieved August 13, 2016, from http://www.tetracam.com/MS\%20Database.htm

Banick, J. L., Lenz, K. E., Jonathan, S., and Zolkowski, J.J., (2015). Monitoring Carbon Dioxide and Methane Levels above Retired Landfill and Forest Control Site with a Tethered Aerostat to Determine Remediation Effectiveness. Proceedings of the Wisconisn Space Conference. Retrieved September 10, 2016 from: https://spacegrant.carthage.edu/ojs/index.php/wsc/article/view/142

Climate Change Causes: A Blanket around the Earth. (n.d.). Retrieved September 15, 2015, from Climate Change: Vital Signs of the Planet website: http://climate.nasa.gov/causes/

Climate Central. (2012). Global Weirdness: Severe Storms, Deadly Heat Waves, Relentless Drought, Rising Seas, and the Weather of the Future. New York, NY: Pantheon Books.

Datasheet: K-30 Sensor [Fact sheet]. (2015, May). Retrieved September 7, 2015, from http://co2meters.com/Documentation/Datasheets/DS30-01\%20-\%20K30.pdf

Feldscher, K. (2011, November 1). Greenhouse Gases Pose Threat to Public Health. [Newsgroup post]. Retrieved from https:/www.hsph.harvard.edu/news/features/bernstein-greenhouse-gases-health-threat/

Perera, M. D., Hettiaratchi, J. P., \& Achari, G. (2002). A mathematical modeling approach to improve the point estimation of landfill gas surface emissions using the flux chamber technique. Journal Of Environmental Engineering \& Science, 1(6), 451-463.

Roston, E. (2008). The Carbon Age: How Life's Core Element Has Become Civilization's Greatest Threat. New York, NY: Walker.

U.S. Environmental Protection Agency List of Municipal Solid Waste Landfills [Image]. (2012, April 2). Retrieved from http://www.epa.gov/epawaste/nonhaz/municipal/landfill/section3.pdf

Fox Valley Technical College. (2016). Wisconsin Map: Fox Valley [Map]. Retreived from www.fvtc.edu/about- us/fvtc-contacts-locations/locations-maps. 